\title{
Flexibility and adaptability - key elements of end-user participation in living space designing
}

\author{
Željko Jakšić ${ }^{1, *}$, Milan Trivunić ${ }^{2}$, Aleksey Adamtsevich ${ }^{3}$ \\ ${ }^{1}$ University of Novi Sad, Faculty of Technical Sciences Novi Sad, Serbia \\ ${ }^{2}$ University of Novi Sad, Faculty of Technical Sciences Novi Sad, Serbia \\ ${ }^{3}$ Moscow State University of Civil Engineering, Yaroslavskoe shosse, 26, Moscow, 129337, Russia
}

\begin{abstract}
An end-user has the main role in the creation of space where spends most of its lifetime (home, workplace). That is why important that a designer (he first) recognizes what requests of the end-user are. In the reference literature and researches that deal with the spatial organisations and designing of living area, the role of an end-user is essential. However, what does the end user participation mean, actually? At what level an enduser makes a final decision? Is it a choice among several alternative solutions provided by an architect or end-user himself? This article precisely deals with that subject - where begins and where ends participation of the end-user when the theme is the final spatial solution and under what circumstances. In this case, habitation represents the much more sensitive area than any other area for human needs or activities. In technical terms, an end-user could be someone who either knows nothing or knows a lot but not enough about both the spatial and functional organisations. His role should be reduced to choice of one from the group of high-quality solutions and, in a technical sense, logical solutions made by an expert. No more than that.
\end{abstract}

\section{Introduction}

Housing occurs in two forms, both the individual and multi-family collective housing, regardless of the environment and well-known levels of housing - from the city to the apartment. Each of these two forms has a certain restriction level, but at the international level, multi-family housing is can be seen as a much more common form of affordable housing. Affordable housing represents two types of the dwelling production:

- adaptation of existing facilities to modern living conditions, and

- building new facilities.

New facilities provide far greater opportunities for achieving the high-quality result, on the one hand, because of complete freedom in the choice of structural systems and construction technology, and on the other one, increasing the possibility of alternative solutions. In the same time, the responsibility of an architect should be higher. A materially and scientific heritage in the field of multi-family dwellings indicate that time wouldn't be the one which gives a final verdict on the achievement anymore. Thanks to inputs like these

*Corresponding author: alt96@uns.ac.rs 
the architect foresight becomes the main tool of conceptual settings. Given that these are the facilities designed and accomplished to a longer period, the percentage of predictability contents of users requires and identifying their needs decreases, tapering, and becomes blurred during the time. Accordingly, obvious there isn't a final solution but a set of more sustainable proposals. That is because two different participants for the same dwelling area can choose two different solutions at the same time (usually, the reasons are following: generation gap, belonging to the dissimilar social, gender or ethnic groups).

\section{The intellection of flexibility and adaptability concept}

In multi-story housing, there is a need for designing flexible plans which would be able to meet uncertain requirements of people. Some authors flexibility considered as an overall notion of the changing in an apartment structure [1]: 'Three types of flexibility exist in the multi-story housing; elasticity, adaptability, and versatility'. Friedman suggests that 'providing occupants with forms and means that facilitate a fit between the space needs and the constraints of their homes either before or after occupancy' [2] is one interpretation of adaptability. Schmidt and colleagues identify four characteristics that have to be included in the definition: "capacity for change, ability to remain "fit" for the purpose, maximizing value, and time (speed of change and through life changes).' As their working definition of adaptability, Adaptable Futures generates 'the capacity of a building to accommodate effectively the evolving demands of its context, thus maximizing value through life' [3]. Schneider and Till in the definition of flexibility further discuss different types of the flexible housing according to the use of 'soft' or 'hard' tactics. Soft tactics are those that allow certain indeterminacy, such as the provision of a room with an indeterminate function. Contrary, hard elements such as sliding and rotating walls are those that determine the precise way in which design can be in use. [4].

One of the progenitors of flexibility Habraken created SAR method that had based on developing a set of standards for the design of stands. It is hard to say he was the pioneer at the issues of flexibility and adaptability, depending on the point of view. Its methodology bases on the building centre line division into a band system (zones), which facilitates designing and locating of various rooms in a house. Opposed to developed countries the production of apartments in Serbia, as a country in transition, passing through a technological stagnation.

Does it mean that the fight for flexibility already lost? Although it seems unbelievable, that is not necessarily a handicap. Why is that so? Unlike to Geraedts opinion [5], there is no causal connection between technology and flexibility/adaptability. It is more likely the matter of idea.

\section{An interconnection between concept and technology}

Some famous architects such as Frank Lloyd Wright, Philip Johnson, Charles and Ray Eames, Jean Prouve, Walter Gropius, and Buckminster Fuller saw emerging production technologies and thought these could be used to design customizable and continually adaptable housing that would be affordable to the masses. Perhaps is overstated to say, but emphatically true, that the idea of 'pre-fab' housing with the idea to utilize industrial technology and factories in building construction to mass-produce housing at an affordable cost is exaggerated and an obsolete (more like one-way observed) approach. Perhaps it is obsolete but not useless.

There is no doubt that 'pre-fab' or 'pre-cast' presents a golden achievement in the technology of the housing production but housing is primary life - a life in the built 
environment, a life and life's moments that being shared within the neighbourhood and in the own family. As we can see, the housing has got more likely spatial and social than technological dimension.

\section{Related works in Adaptable Housing area}

Micaela Danko also highlights the importance of Habraken ideas about the stratification of the housing structure, so called by him as 'support'; which consist of the primary structure, building envelope, circulation spaces, and mechanical systems, that later has developed into the concept of Open Building. This upgraded concept contains several characteristic elements, but two of them can be singled out as key determinants of the whole concept:

- users/inhabitants may make design decisions as well, and

- built environment is the product of an ongoing, never ending, design process in which environment transforms part by part and they are the start point of our research. [6].

\section{User as a decision maker}

Newly created circumstances in the production process and facilities usage tend to become world process through the definition of universal. It needs to be through the definition of universal and flexible enough standards translated as an application in understandable language to all stakeholders. Exactly, for this reason, due to much complicity for defining final solutions based on an end-user requests, it is necessary to make a clear communication with a final algorithm that has not given as the only possible. Models are available and numerous. Creating such holistic valuation model appears as a real need for the choice of optimal housing and living environment for its users. It is according to their requirements and economic opportunities. This is important when it comes to the unbuilt (new) facilities or facilities that are in use, either as newly constructed or as secondary structures with the certain period of depreciation. Constructing new facilities and after its finishing launches a series of operations before performing, like the planning, programming, select a satisfactory solution at the program level, design, implementation, final evaluation, use, and maintenance, which includes the final result closely equal to the demands of potential users. The participation of tenants is less restrictive in this way respectively has got the highest degree of freedom.

It is necessary to highlight the importance of defining professional affordability level when the partner dialogue is being concretised on the basic level (the partners are an enduser and an architect), i.e. level on which the decision-making process of an end-user (as a layman) is acquitted from subjective opinion. Such a relationship is more successful if the system is regulated:

- from general - information level,

- via an organisation level (a level of services related to project documentation before the construction of the facility),

- to the operational level - the construction, usage and maintenance level of facilities.

The picture has completed as follows (Fig. 1): Information level

- An information centre, divided upon the sectors of main citizens needs in the sense of housing - built area - a spatial housing planning -an information phase I.

- Acquainting with contractors (and subcontractors) - I, II, III phase of an education getting.

- Acquainting with companies specialized in the maintenance of facilities - I, II, III phase of the dialogue. 


\section{Organization level}

- Represents (displays) a process of the project development from the beginning to its finish - Phase I: Education.

- Defining an accessible level of the tenant making a decision - Phase II: Education.

- A checklist that provides direct contact users/developer - Phase III: Dialogue (interview).

- Performance requirement resulting from the demands of end-users - Phase IV: Dialogue (performance specifications).

Operational level

- Acquainting the end-users with materials supplier, components, and elements - I, II, III phase of information getting.

- Acquainting with contractors (and subcontractors) - I, II, III phase of an education getting.

- Acquainting with companies specialized in the maintenance of facilities - I, II, III phase of the dialogue.

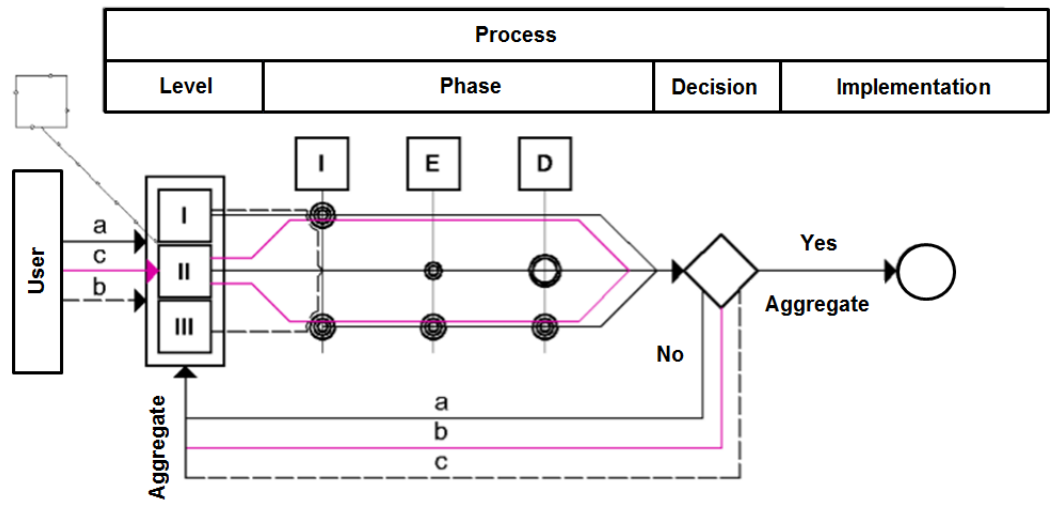

\begin{tabular}{|r|l|l|l|}
\hline I & Information level & I & Information \\
\cline { 1 - 1 } II & organizational level & E & Education \\
\hline III & operational level & D & Dialogue \\
\hline & changeable level & & \\
\hline
\end{tabular}

\begin{tabular}{|c|c|c|c|}
\hline \multicolumn{2}{|c|}{ Users' line } & \multicolumn{2}{|r|}{ Phase } \\
\hline a - & Independently I and II, III with II (tutor) to the end & 0 & Phase I \\
\hline b - & Independently I and III, with II (tutor) to the end & 0 & Phase II \\
\hline$c-$ & with II (tutor) to the end & $\mathrm{O}$ & Phase III \\
\hline tutor & a designer (usually an architect) & O & Phase IV \\
\hline
\end{tabular}

Fig. 1. Directions (routes) of user's participation or the 'logical (rational) path' method [7]

It is necessary to highlight that the mentioned levels do not condition each other, so the system does not need to be arranged and closed, although such a condition are recommended. More precisely, when this area is arranged in the initial phase it is possible the separate operation of arranged parts. However automatically, gradually appears the chain reaction, in the form of self-arranging due to arranged nature of the performance principles. In the feedback loop, an architect can appear as a coordinator all these levels. If the satisfactory result does not arise after a few iterations, the tutor (architect) could be eliminated from an overall process and changed with a new one. 
The entire process end-users can conduct by themselves and more or less well-done it will depend on its foreknowledge (commonly incorrect). Eventually, the end-user has the major role in own space creating where spends the most of its free time per a day. Stability, safety, and security are the common action issues of users and architects, namely neither with regulations it cannot be achieved without the participation of experts. Even the final level (apartment furnishing) has got the variant solutions proposed by the designer.

\section{The limit that cannot be crossed}

After all of these definitions, what kind of flexibility or adaptability we are going to adopt now? We choose the one from Serbia - the notion "flexibility" has meaning equal as "adaptability" but in different stages of apartment materialization. The changes use during the design process is being called flexibility while adaptability using in the meaning of changes of an apartment during its exploitation process [8]. Earlier in this article, it was promoted Habraken as the progenitor of flexibility and his theory of 'supports'.

We agree that 'supports' provide a basic infrastructure designed as a long-life permanent base. Infill are the shorter lifetime, determined and adapted by the user.

Looking for pure spatial flexibility, worldwide researchers keep trying to discover all possible limitations. But the limitations are not of the same kind. Some of them are crucial. Here are some of them: building structure (of any technology - Fig. 2), a typical organization of unit and, of course, supplies (installations), especially sewerage system. It is important to underline the fact that outer part of the flat (flat shell) could be made of any kind the structure and material while the interior is without the structural elements.

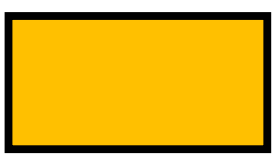

a)

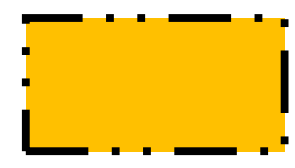

b)

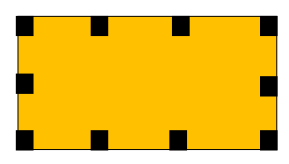

c)

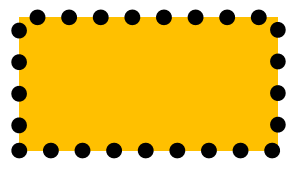

d)

a) mass wall - ceramic elements or of another material

b) precast wall - mass wall or combined with columns

c) reinforcement concrete skeletal system

d) steel skeletal system (most adaptable)

Fig. 2. Flat shell in combination with any kind material or structure

\section{What would be defined and offered by designer to users}

A conceptual consideration in flexing housing design is the question of how much the design should be determinate by an architect or an end-user. In the book Flexible Housing (Schneider \& Till, 2005) the authors describe two different approaches, 'soft and hard' that designers apply to their project to a varying degree. The soft approach allows for indeterminacy of spaces in which the users are allowed to change the space to suit their needs, while the building architect works in the background. The hard approach, in which the architect exerts more control in the design, creates spaces that may have predetermined uses and flexibility options.

There is dimness. What the term indeterminacy exactly means? What its limits are? The process of meet wills and needs of occupants must not exclude an architect. On the contrary, an architect needs to suggest and gives the solutions whereas tenants choose only. The following are proposed elements that must be defined by an architect without any outward influences: 
- Freedom to the designers during an overall designing process.

- Designer shapes a housing unit by using own skills and knowledge.

- Structural system and coating (covering) of a building according to national legislative (Fig.2.).

- Analysing all the possible (optimal) solutions of apartment unit to meet at least minimum tenant's requirements (defined by national legislation).

- To adjust floor slab with an aim to provide a smooth functionality of the sewer system.

This and-users' participation reminds on buying from the catalogue.

\section{A vision of flexibility - a suggestion}

When habitation is being summarized at a basic level, it needs a step back toward the previous one - the housing unit. That level implies an organization which contains the optimal number of apartments on a floor and every apartment has to be at least with two orientations.
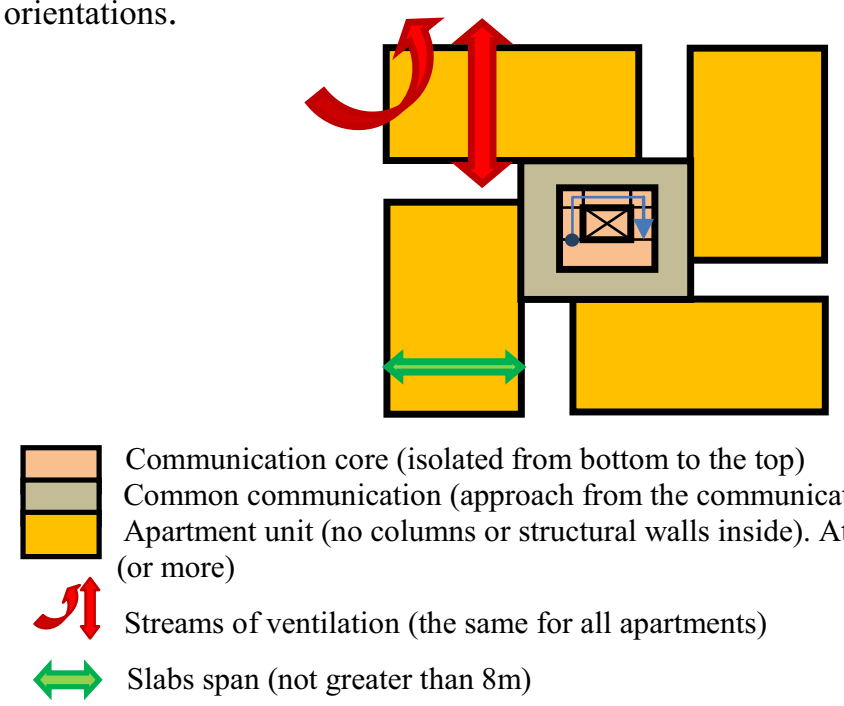

Communication core (isolated from bottom to the top)

Common communication (approach from the communication core is controlled)

Apartment unit (no columns or structural walls inside). At least double oriented apartments (or more)

Streams of ventilation (the same for all apartments)

Slabs span (not greater than $8 \mathrm{~m}$ )

Fig. 3. One vision of the flexibility (raises the changing capacity level)

That means that healthy life elements and energy efficiency are taken into account as security as well. The variety of an apartment unit organization shown in the figure below has chosen as an example with one flat, although, a unit can be divided - into two parts equal or different sizes.
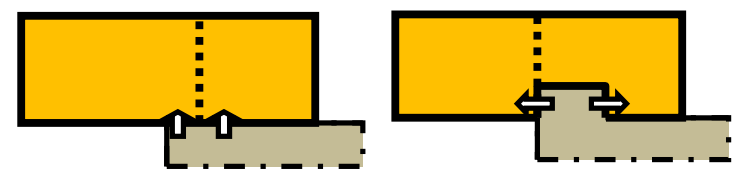

a) The apartments of different sizes

1,2 - apartments

$\Rightarrow$-apartments entrance

...-apartments boundaries

Fig. 4. A detail of an apartment unit - varieties of the divide

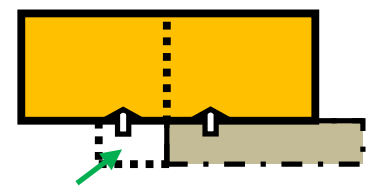

Extended due to the equal divides of apartments

b) The same sizes of apartments 
While the efficient sewage system is not well designed, then the empty inner space highest level is not satisfied properly. This one implies setting an 'installation corridor' (fig. 5.).

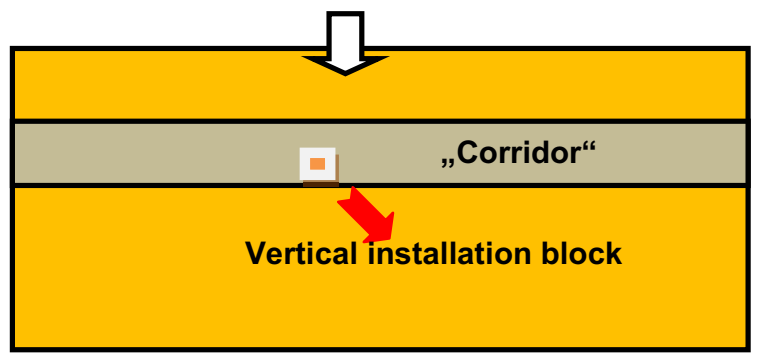

Fig. 5. Vertical installation block in the 'corridor' fits up within the future organization of an apartment

Therefore, it is necessary to perform a floor slab in a different way than usual. Something similarly was suggested by Kendall [9] - fig. 6a and Jakšić [7]- fig. 6b in their researches, where the 'empty' space inside the slab has provided by the technological manners. The primary aim of this organization is to allow undisturbed partitions displacement while installations are available in any situation. In the same time, the tenants below are not physically disturbed. In according to the given solutions for slabs in the previous text (Kendall, Jakšić), the proposed one will entail a more economical product.
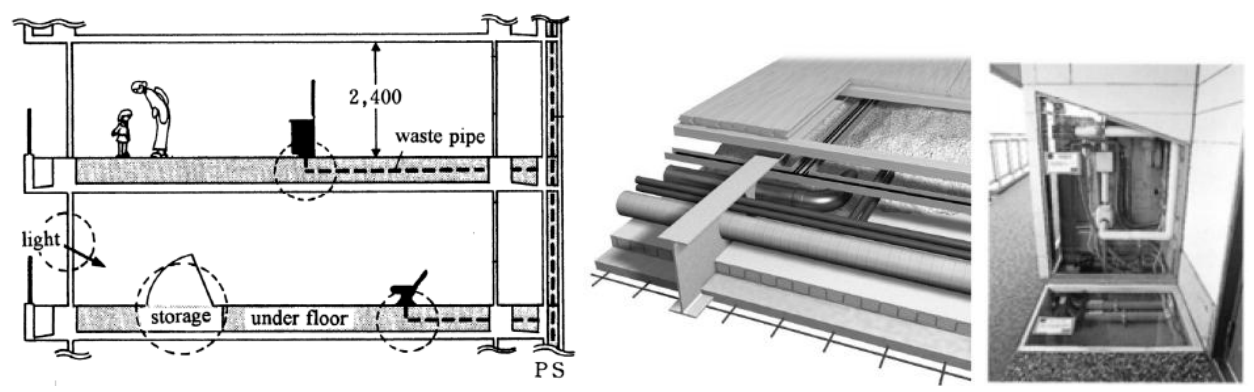

Fig. 6a. Using traditional materials assembled in new ways [9]

Space span in dependency on both complexity of supplies installations and the distance between them defined by the standards

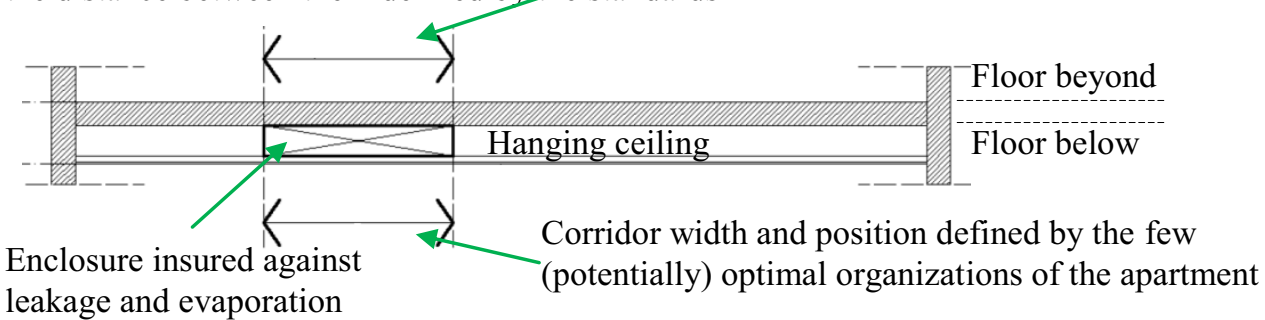

Fig. 6b.'Corridor' has placed beyond the hanging ceiling [7] 


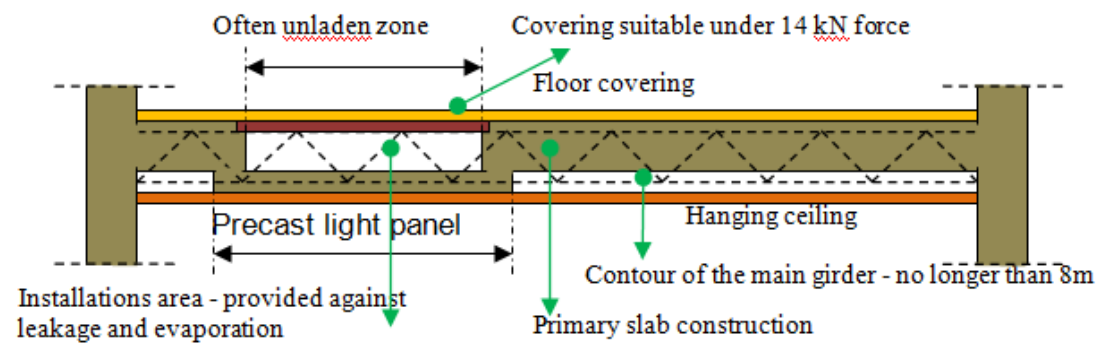

Fig. 7. Combined slab

Causality between 'corridor' position and the number of optimal layouts is shown below in fig. 8 . Those patterns have to forward to the end-users in order to be capable making choices on an easier way.
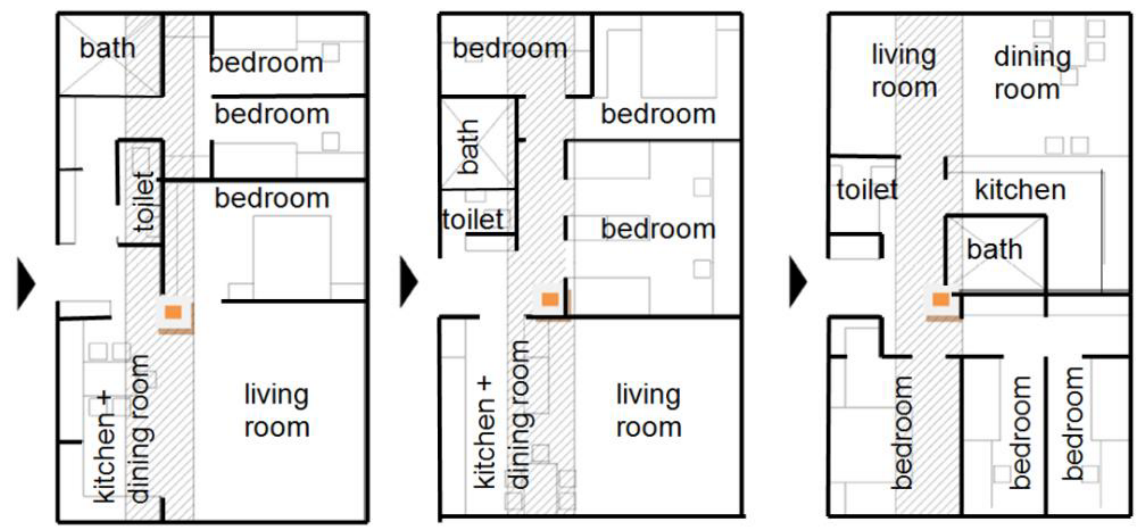

Fig. 8. Possible layout solutions

\section{Results discussion}

To create the realistic picture of proposed solutions, it needs to take a look at their basic features:

- Increased construction costs due to the slab complexity.

- By creating the space in-between of the slab increases a building height (or reduces the number of floors).

- It is necessary to corridor be accessible by the side of the apartment to whom belongs, so that this area must be flexible, movable.

- An installation corridor's position still conditioned by the number of possible optimum solutions and the logical organization of the apartment with the restrooms located in the corridor or contacting him.

- The highest degree of technical freedom allows the space of structure independent, respectively, the apartment space located in one constructive span.

- The numerous organizations of different solutions of an apartment conditioned by its orientation(s). The apartment with a large number of free façades towards the environment provides the higher level of freedom in the contents organizing.

Installation corridor as a subset of the supply system (especially sewerage) of housing unit requires specific approach in its planning and performing, in order, its application 
would be possible at all. It is necessary to provide a 'margin' or reserve space (Look at fig. 8 - vertical cross-section through slab) that has to be ensured by leakage and evaporation. The key to this design is the nature of ownership of property. There are two forms:

- The one level apartment (multi-family housing) and accessible only from the slab top so that there aren't any common points with the neighbours below and then don't disturb them.

- Within a duplex apartment (usually at individual housing) located in the corridor (inbetween the slab and hanging ceiling).

Any of these cases implies the special approach in slab structure that requires additional expenses, work, and workers as well. This is obviously worth.

\section{Conclusions}

In multi-story housing, there is a need for designing flexible plans which would be able to meet uncertain requirements of people. In preliminary part of the paper are presented some prestige theories which relate to flexibility and adaptability. As can be seen, each of them deals with the causal connections between technology, construction, empty space, on one side, and almost unconditional participation of the and-user, on the other one. This theme opens a few questions. Here are some of crucial: a) where are the limits of flexibility; b) does the flexibility and adaptability depend on technology; c) what is the space of freedom 'dedicated' to an end-user; d) when an end-user makes the choice without an architect influence?

The second part of the paper gives the answers to some of the questions containing the proposals that lead to not exceeded limits of flexibility and adaptability. It stated that technology is an important but not the sufficient condition for the sustainability of the idea of flexibility and adaptability. Much serious role drives the structure and supplies systems, especially sewer system. According to the requirements of end users of healthy living and energy efficiency, an organization of housing unit has been proposed. At the same time, as far as constructive elements allow the emptiness (free space) inside of boundaries of an apartment was analysed.

These analyses showed that without structural elements inside an apartment space and sewer installations placed in one position raises the space width degree of an apartment on the level that eventually couldn't be overdrive.

The main conclusion has related to an apartment freely from the structural system and sewerage placed in one position and at the same time, a crucial role of an architect in making a choice for any future tenant. Everyone has the right to choose the solutions released of any influence of an architect. But it is much easier making a choice between solutions offered by designers (usually architects).

\section{References}

1. L. A. Moharram, A method for evaluating the flexibility of floor plans in multi-story housing, DAI-A 41/06, Dissertation Abstracts International, University of Pennsylvania, United States, Dissertations \& Theses (1980)

Document URL: http://search.proquest.com/docview/288148416

2. A. Friedman, The Adaptable House: Designing Homes for Change, McGrawHillProfessional (2002).

3. R. Schmidt III and T. Eguchi, S. Austin, and A. Gibb, What is the Meaning of Adaptability in the Building Industry, Bilbao, Spain (2010).

4. T. Schneider, and J. Till, Flexible Housing. TF, (2007) 
5. R. Geraedts, Success and failure in the flexible building, International Conference Sustainable Open Building, May 2010, Bilbao, Spain, 2010.

6. M. R. Danko, Designing Affordable Housing for Adaptability: Principles, Practices, \& Application, 2013, Pitzer Senior Theses, Paper 35 (2013).

7. Ž. Jakšić, The concept of performance and use the value of housing in multifamily housing facilities, Dissertation, FTS Novi Sad, Serbia (2007). (In Serbian)

8. R. Trbojević, Combinability functional elements in precast housing construction, University in Belgrade, Faculty of Architecture (in Serbian) (1980)

9. S. Kendall, Taking stock of emerging patterns of control in the making of built environment, Proceedings of the 16th International conference of the CIB W104 Open building implementation on 'Open and sustainable building', Bilbao, Spain, 14 (2010).

10. BV Decisio, BeleidsevaluatieDemonstratieprogramma IFDbouwen (MED program IFD); TNO, TNS NIPO enOranjewoud, Amsterdam (2006).

11. N. J. Habraken, Supports: An Alternative to Mass Housing, London: AP, (1972).

12. B. Jürgenhake, The façade - mediator between inside and outside, W, 18 - Residential Environments and People, 'Housing in an expanding Europe: theory, policy, participation and implementation' Ljubljana, Slovenia, 2 - 5 July, (2006).

13. G. Maccreanor, Adaptability, Housing and flexibility I, a+t 12, 43 (1998).

14. T. Schneider, and J. Till, Flexible Housing: opportunities and limits. t, Cambridge Journals, (2005)

15. D. A. Vandenbroucke, Housing Affordability Data System, HUD (2011)

Document URL: http://www.huduser.org/portal/datasets/hads/HADS_doc.pdf. 